\title{
The Internet and the Global Monitoring of Emerging Diseases: Lessons from the First 10 Years of ProMED-mail
}

\author{
Lawrence C. Madoff ${ }^{\mathrm{a}}$ and John P. Woodall ${ }^{\mathrm{b}}$ \\ ProMED-mail, International Society for Infectious Diseases, ${ }^{\mathrm{a} B r i g h a m}$ and Women's Hospital, Harvard Medical School, Boston, Massachusetts \\ and ${ }^{\mathrm{b}}$ Nucleus for the Investigation of Emerging Infectious Diseases, Institute of Medical Biochemistry, Center for Health Sciences, \\ Federal University of Rio de Janeiro, Brazil
}

Received for publication June 3, 2005; accepted June 7, 2005 (ARCMED-D-05-00214).

\begin{abstract}
Now in its eleventh year, ProMED-mail is a robust and sensitive mechanism for the discovery of emerging disease outbreaks involving humans, animals, and plants around the world and for rapid dissemination of information. Fast reporting translates into quicker arrival of prevention and control assistance from other countries, better advance warning to neighboring countries and intending travelers, and other benefits to public health such as heightened awareness of health workers to the threat, time to prepare countermeasures and to react in an appropriate manner rather than a reflex emergency response. (c) 2005 IMSS. Published by Elsevier Inc.
\end{abstract}

Key Words: Emerging diseases, Disease surveillance, Epidemiology of infectious diseases, Bioterrorism, Biological warfare.

\section{Introduction}

The year was 1993 and to some attendees at a conference in Geneva co-sponsored by the Federation of American Scientists (FAS) and the World Health Organization (WHO), the convergence of two important trends was becoming apparent. The first was the role of emerging infectious diseases in a world buffeted by HIV and a renewed threat of biological warfare. The second was the dramatic coming of age of the Internet. Once the realm of academic scientists, the dawn of the worldwide web and the extensive adoption of electronic mail heralded an era of instantaneous global communication. Thus was born ProMED, the Program for Monitoring Emerging Diseases. FAS is a center of policy research, analysis and education sponsored by more than 40 American Nobel Laureates and with a strong interest in disarmament. ProMED was chaired by Professor Stephen S. Morse, then of Rockefeller University, and Professor Barbara Hatch Rosenberg of the State University of New York-Purchase was FAS Coordinator for ProMED. The program covered emerging infectious diseases and toxins of humans, animals (domes-

Address reprint requests to: Lawrence C. Madoff, M.D., International Society for Infectious Diseases, Channing Laboratory, Brigham and Women's Hospital, Harvard Medical School, 181 Longwood Avenue, Boston, MA 02115; E-mail: lmadoff@promedmail.org tic, wild and captive) and crop plants and the threat posed by their potential use for bioterrorism.

At a follow-up conference in the U.S. in 1994, attendees joined an e-mail list that allowed them to stay in touch with one another and share news in their field. It began with some 40 subscribers, but as news of outbreaks spread among these inaugural subscribers was forwarded to colleagues, others sought to subscribe to the list and within months hundreds joined. The list was named ProMED-mail (PMM).

From the beginning, PMM has had some simple concepts in mind. The goal was, and has always been, to serve global public health by acting as an early warning system for outbreaks of emerging diseases. The following section gives an historical overview of PMM's first 11 years in order to provide the reader with an understanding of the numerous ways in which PMM has developed and served the public health community. A brief summary of how PMM currently operates will be provided and, finally, some of our more recent projects to develop regional networks will be summarized.

\section{PMM Timeline 1994-2005}

1994: PMM was first directed by one of the authors (J.W.), then of the New York State Department of Health, Albany, 
NY. It was hosted free of charge by SatelLife, a health communications system then directed by Charles Clements, created by Dr. Bernard Lown, co-founder of the Nobel Prize-winning International Physicians for the Prevention of Nuclear War, based in Cambridge, Massachusetts. The first e-mail outbreak report was sent in August 1994 to 40 subscribers in seven countries, reporting the case of laboratory infection in the U.S. with Sabia virus, the cause of Brazilian hemorrhagic fever, thus calling attention to the need for greater biosafety measures in research laboratories.

In November 1994, PMM was opened to the public, at no cost for subscribing. Thanks to publicity at the American Society of Tropical Medicine and Hygiene's annual meeting and to an invitation posted on the Virology Newsgroup on the Internet, the number of subscribers rose to 250 by the end of the year. Notable reports posted by PMM in 1994 were about plague in India, the death of several racehorses and their trainer in Australia (subsequently found to be due to a new agent named Hendra virus), the identification of a new species of Ehrlichia causing human granulocytic ehrlichiosis in the U.S., and a banana disease causing severe crop losses in Costa Rica.

1995: In a gesture of official recognition, the Australian government health agency sent directly to PMM its report on the first recognized cases of Japanese encephalitis virus in Australia.

The number of free subscribers rose slowly to 750 , in 44 countries, and then in May the news of the Ebola outbreak in Kikwit in the Democratic Republic of the Congo (then Zaire) hit the Internet, websurfers got to hear it was being reported by PMM, and subscriber numbers more than doubled almost overnight. The year ended with almost 3500 direct subscribers from more than 90 countries, plus a large secondary distribution through SatelLife's HealthNet (Africa and Asia), DocNet (Sweden), Peter Saville (Fiji for the South Pacific) and other friendly disseminators. MEDSCAPE reported they had several hundred hits on the PMM digests made accessible at their Website. Traffic increased from about 10 postings a week to 10 or more per day. In order to focus the list more closely on emerging diseases, reports of HIV/AIDS, tuberculosis and malaria were dropped, except in cases of an extension of range or an increase in drug or vector resistance.

All messages sent to PMM were moderated before posting by a panel of specialists that included, besides Drs. Morse and author J.W. (virologists): Charles H. Calisher, Professor, Department of Microbiology, Colorado State University, Fort Collins, Colorado (virologist), and Martin Hugh-Jones, Director, WHO Collaborating Center for Reference and Training in Remote Sensing and Geographic Information Systems for Veterinary Public Health, Louisiana State University, Baton Rouge, Louisiana (veterinarian).

1996: On 28 May 1996 a subscriber in Manila watching local TV news told PMM about a big outbreak of cholera in the Philippines, which PMM posted immediately. WHO was not authorized by that country to put it on the WHO electronic bulletin until 14 June. On 7 June 1996, the Director of the WHO Collaborating Centre for Dengue Fever/Dengue Hemorrhagic Fever in Kuala Lumpur advised us of the start of the dengue season in Malaysia, with 2450 cases reported.

An infectious disease specialist in Switzerland joined PMM, mentioning in passing that he had just diagnosed a fatal case of yellow fever in his hospital. The patient was a Swiss tourist who had visited the Brazilian Amazon. There was some delay in persuading the doctor to give permission to publish, but the report was posted on PMM on July 1, with the doctor's note that he hoped this would encourage would-be tourists to get their yellow fever shots. WHO reported some time later. The importance of early widespread notification of events like this is shown by the fact that another uninformed tourist traveled to the same part of Brazil without being vaccinated, in August 1996, and died after returning to the U.S.

In June 1996, an epidemiologist with the health services department of the County of Los Angeles, California asked for confirmation of a report from a local Japanese newspaper reporter that there was an outbreak of $E$. coli in schoolchildren in Japan. Within 4 days, the doctor in charge of the Hiroshima Quarantine Station in Japan replied with a day-by-day account of the spread of the outbreak, translated from local newspapers.

On Saturday, 21 September 1996, PMM received an e-mail call for help from the Division of Emergency Medicine of the All India Institute of Medical Sciences. Children were dying of DHF in their wards and they needed information on treatment. The call was seen by the WHO Regional Office for South East Asia, also located in Delhi, and on the following Monday a team drove to the hospital and provided the needed assistance.

PMM posted on a new Ebola outbreak in Gabon before WHO Geneva. The fact that all these reports were later confirmed by WHO headquarters in Switzerland testifies to the reliability of the reports coming in to PMM.

The State Epidemiologist for Russia sent reports of outbreaks of infectious disease every week or so during much of 1996, until a reorganization of his office intervened. In August, the Regional Epidemiology Office based in New York State put out a warning through phone, fax and PMM, concerning a batch of renal dialysis fluid that was causing toxic reactions in kidney dialysis patients in the northeastern U.S. The post on PMM contributed to the identification of 73 cases.

ProMED-PLANT, a sublist on plant disease, was launched, moderated by plant virologist Pamela Anderson of the International Center for Tropical Agriculture (CIAT), Cali, Colombia. The number of PMM subscribers exploded from 700 in April 1995 to 7000 in November 1996-a 10 -fold increase in 20 months. 
1997: In March 1997 the National Institute of Virology of South Africa sent PMM a message that a cemetery containing the remains of long-buried smallpox victims was to be excavated to permit the construction of low-cost housing. They wanted to know the chances of the smallpox virus having survived burial for 30 years. A world expert on smallpox replied that there was no danger, but to allay public concern it would be a good idea to have the people who would be handling the remains vaccinated against smallpox.

On 31 July the Wall Street Journal published a story on PMM on the front page of the Business Section, and over the next 17 days, 560 new subscribers joined, most of them probably because of the publicity. By the end of 1997 there were over 11,000 direct subscribers in more than 135 countries-and thousands more via the Web. PMM subscribers included, among others:

* World Health Organization (WHO)

* United Nations humanitarian and relief agencies

* Federation of International Red Cross and Red Crescent Societies

* U.S. Centers for Disease Control and Prevention (CDC)

* Laboratory Centers for Disease Control, Canada

* Public Health Laboratory Service, UK

* Pasteur Institutes in France, Tahiti, Vietnam

* National Institute of Health, Japan

and national health ministries and departments worldwide, as well as thousands of interested members of the general public.

ProMED-PORT was established as a parallel list in both Spanish and Portuguese for reporting and discussing emerging infectious diseases in those languages, on the assumption that some Latin American biomedical scientists might feel more comfortable discussing outbreaks in their native languages. It has been moderated from the start by Dr. Luiz Jacintho da Silva, professor at the Faculty of Medical Sciences, Unicamp, São Paulo, Brazil. To handle the increasing volume of traffic, PMM contracted in September 1997 a part-time Managing Editor, Edward Schroder of Boston University and a computer specialist, Phil Temples, to make corrections to archives, run statistics, and recruit subscribers. In addition, in order to improve the geographical distribution and regional expertise of the team, a Regional Moderator, Alex Vladyko of Belarus, was added at the end of the year.

A notable 1997 report was that of an outbreak of meningococcal meningitis in Vietnamese immigrants in Moscow, at first officially denied to PMM by the State Secretary of Epidemiology but then confirmed by the Director of the Laboratory for Meningococcal Infection and Bacterial Meningitis in Moscow. A PMM subscriber in Brazil forwarded a local newspaper report of an outbreak in the remote Upper Amazon province of Acre, of rash, bloody diarrhea and vomiting, which had killed 27 people in 20 days. Soon an e-mail message came in from Acre, from a doctor involved in the investigation of the cases there, with the laboratory diagnosis of delta hepatitis.

More official recognition of the status of PMM came in the form of another report from the Australian government health agency, sent directly to PMM, of a new rabies-like virus from fruit bats, associated with a human death, and another from the Undersecretary of Health of Chile of an outbreak of amebiasis in a coastal city.

PMM made at least two significant contributions to public health preparedness in 1997. First, one of our moderators, Charles Calisher, became concerned at the reports he was moderating of cases of Lassa fever in Sierra Leone, West Africa, at the time that civilians were to be evacuated from the civil war zone there, and U.S. troops might have had to go ashore and become exposed to the disease. With a collaborator he convinced the U.S. Navy to provide a supply of the antiviral drug ribovirin to the offshore fleet. Second, PMM posted an item saying that enteroviruses had been found to survive the chemical treatment in aircraft toilets. A member of the British national disaster management team told us that reading this post had led him to recommend new precautions for emergency personnel dealing with crashed aircraft.

PMM publicized the case of Dr. Desi Mendoza Rivero of Cuba, who was imprisoned for publicly questioning the official government figures for the number of cases in the dengue epidemic there and brought it to the attention of Amnesty International and Physicians for Human Rights. PMM deplores any interference in the free distribution of information about matters of public health importance, specifically about outbreaks of infectious disease.

1998: During the year PMM posted reports of 616 new outbreaks, including 236 of animal diseases or zoonoses, and 4 of plant diseases. Updates, discussion of outbreaks, and other business took the total messages posted to 2470 , an average of seven per day, 7 days a week. PMM posted three public health alerts and 12 advisories during the year, on such topics as botulism in bottled vegetables, a dropsy epidemic (in Nepal), influenza A, Listeria contamination, red tide, Salmonella/E.coli in alfalfa sprouts, and tuberculosis in aircraft passengers.

People have risked their lives and liberty to contribute to PMM. Dr. Louise Martin, a CDC veterinarian investigating the 1997-1998 Rift Valley fever outbreak in Kenya, and frequent contributor to PMM from the field there, died in the U.S. Embassy bombing in Nairobi while picking up her mail. Dr. Tan Poh Tin of Malaysia, at the very real risk of prosecution for divulging information before its official release, sent details of 27 pediatric cases of the fatal hand, foot and mouth disease of which she had personal knowledge, with information on treatment, for posting on PMM.

1999: On Sunday, 4 April 1999, ProMED-mail received and posted, direct from the Pasteur Institute, Madagascar, 
the report of the first cases of cholera ever reported from that country. WHO put this on its restricted Outbreak Verification List 3 days later, acknowledging ProMED-mail as a source. In 1999 ProMED-mail was able to report cholera outbreaks in 11 countries, 3 days to 8 weeks (in the case of cholera in Peru) before WHO was able to, because WHO had to wait for country clearance. ProMED-mail also reported plague outbreaks in eight countries, 11 days to 4 weeks (in the case of plague in Colorado in the U.S.) before WHO could, for the same reason.

Other outbreaks appearing for the first time in 1999 included African horse sickness in South Africa, black sigatoka of bananas in Brazil, cowpox in cattle and humans in Brazil, fungal brown spot of citrus in Israel and Turkey, a new influenza A strain in swine in the U.S., Japanese encephalitis/Nipah (Hendra-like) virus in Malaysia and Singapore, and Legionellosis traced to a nebulizer at a flower show in the Netherlands. PMM posted, as a public service, 40 health advisories, alerts, product recalls and warnings during the year. A notable report was of yellow fever in Bolivia, posted by PMM in February 1999 with regular follow-ups, but not officially notified by Bolivia and published by the WHO until 9 days later. Note that in all cases the PMM report was subsequently officially confirmed. PMM complements WHO's global surveillance system by rapidly disseminating media and subscriber reports of new outbreaks, giving early warning of epidemics which can be further investigated by WHO and the countries concerned.

PMM moved in October from the Federation of American Scientists (FAS) and SatelLife, which together nursed the list through its first 5 years, to a collaboration with the International Society for Infectious Diseases (ISID), Harvard School of Public Health, and the Oracle Corporation. PMM had outgrown the technical facilities of SatelLife and was out of the mainstream of FAS's new interests, so the collaboration with ISID, a nonprofit professional organization with 20,000 members worldwide, makes excellent sense.

In 1999, the Narita Airport Quarantine office, Tokyo, Japan, began regularly translating PMM posts into Japanese.

2000: In January/February 2000, PMM posted reports from three countries (El Salvador, Lesotho, and Peru) from which WHO received no official notification of cholera during the same period. In March 2000, in the case of an outbreak of undiagnosed disease in Pakistan, later found to be pulmonary tuberculosis, WHO credited PMM on its restricted Outbreak Verification List as the source of its report. Another notable report was of anthrax in a drug addict in Norway who injected contaminated heroin. The PMM post led to a Europe-wide re-evaluation of suspected narcotic drug overdose deaths, which in turn uncovered a number of unsuspected cases of Clostridium novyi infection of the injection site.
PMM expanded its staff of expert moderators and editors by hiring a new managing editor, Dan Shapiro, and by creating and filling the positions of parasitic diseases and epidemiology moderators. A copy editor, Paul Guttry, was added to the PMM staff. PMM successfully moved the e-mail discussion lists and web site to computers located at Harvard School of Public Health and Oracle Corporation, respectively. The relocation ensured a stable home on the Internet to allow for rapid, reliable reporting of outbreaks with no constraints on the growth of PMM. PMM's web site, www.promedmail.org, with all the latest PMM reports, rapidly searchable archives, and important infectious disease links, received approximately 4,000 hits per day.

2001: PMM gained many subscribers after the 9/11 terrorist attacks and the subsequent anthrax-by-mail attacks. A comment from one of the moderators on the anthrax attack was mentioned in the New York Times, and D.A. Henderson, then director of the Office of Public Health Preparedness of the U.S., wrote to PMM congratulating it on being one of his office's chief sources of information on the anthrax attack.

An estimated 3,000-4,000 readers viewed PMM reports through secondary distribution channels, and thousands more viewed reports by visiting the PMM web site. In 2001, the average number of visitors to the PMM web site was 12,000 per month, with $40 \%$ from outside the U.S. Peak usage of the web site occurred in October during the unfolding of the anthrax attacks in the U.S. The anthrax incidents in the U.S. in 2001 erased assumptions that the use of infectious pathogens as agents of biological warfare was a remote possibility. Since then, biological warfare and bioterrorism have developed as major themes in the world. Feedback received from subscribers and other readers during the anthrax incidents indicated that they valued the coverage provided by PMM.

In 2001, ISID and the Asociación Panamericana de Infectología (API-Pan-American Society for Infectious Diseases) forged a partnership to create and to promote ProMED-ESP, an enhanced Spanish language version of PMM. The purpose of this joint initiative was to facilitate access to information by physicians and public health workers in Latin America and Spain and to increase reporting of emerging disease outbreaks as well as the number of subscribers from these regions. ISID and API launched ProMED-ESP in June 2001. Extensive communication between the English and Spanish lists allows for the reporting of major outbreaks in both languages. However, the response to these two lists has been disappointing, with only a little over 1000 subscribers on each.

2002: At the end of 2002 the PMM team consisted of one editor, five associate editors, ten subject area moderators, one copy editor, one Spanish translator, and two computer support specialists. In February 2002, ISID named author L.M. as the new Editor of PMM. From 2000 
to 2002, the PMM team grew from 13 to 20 staff members located in nine countries. Three additional associate editors were hired to improve the total reporting capacity of PMM. Three new disease moderators were added to the team to address reports in the following areas: animal diseases and zoonoses, bacterial diseases, and the Latin America region. In addition, a medically oriented Spanish translator joined PMM to translate reports for ProMED-ESP. ISID began to develop potential similar projects with infectious disease societies in Russia and regional surveillance networks in East Africa and Southeast Asia.

In 2002, PMM received a grant from the Rockefeller Foundation to undertake planning for the establishment of a collaboration between PMM and the Mekong Basin Disease Surveillance network (MBDS) in Southeast Asia and between PMM and the East Africa Infectious Diseases Surveillance Network (EAIDSnet). The goal is to enhance the effectiveness of both networks and to assist the regional networks in reaching their objectives. In Southeast Asia specifically, PMM proposed to assist MBDS in establishing an electronic sub-regional surveillance and information exchange network for the priority diseases identified for prevention and control among the six participating countries (Cambodia, Yunnan Province in China, Lao PDR, Myanmar, Thailand and Vietnam). This effort has been led by Associate Editor Marjorie Pollack.

PMM also began a collaboration with the Center for Applied Microbiological Research in the U.K. (now a part of the British Health Protection Agency) to develop a realtime mapping interface for PMM reports. This will allow reports to be linked with world and regional maps and provide a user-friendly and intuitive mechanism for tracking the distribution of outbreaks and disease occurrence. CAMR began by 'geocoding' all 2002 reports.

PMM now counted more than 2500 subscribers from the national governments of 26 countries, from thousands in the U.S. to a solitary one in Christmas Island, including 1400 subscribers from 54 U.S. government agencies-more than 500 of those from the Centers for Disease Control and Prevention (CDC) - and more than 1300 from the health departments of all 50 U.S. states. South Korea launched its version of ProMED, named K-ProMED, with translations of PMM posts.

In 2002, WHO credited PMM as the source of its reports of outbreaks of Q fever in Bosnia, measles in Papua New Guinea, diphtheria in Paraguay and yellow fever in Bolivia. PMM's reports on the spread of West Nile virus in the U.S. were frequently in advance of official listings, and posts on outbreaks of African horse sickness in South Africa, scrapie in sheep in Iowa in the U.S., and foot and mouth disease in Syria were all ahead of official confirmation.

2003: SARS, perhaps the prototypical emerging disease, smoldered through Guanzhou, China, in late 2002 and first became known to the western world through a PMM report on February 10, 2003. Through this and hundreds of subsequent PMM reports, doctors, scientists, public health officials and the general public learned of SARS. In medical and scientific journals and the public press, PMM was widely credited with breaking the story and providing critical details that helped SARS be recognized and its cause discovered with unprecedented speed. In addition to SARS, 2003 was marked by important reports of avian influenza (some causing human disease), monkeypox in the U.S., and an ongoing outbreak of Ebola in the Republic of the Congo.

PMM extended its collaboration with the Mekong Basin Disease Surveillance Group. With the planning grant from the Rockefeller Foundation, work continued on developing a network within the Mekong region to improve reporting of infectious diseases in this region (see section above). As part of this project, PMM will also develop collaborations with the East African Integrated Disease Surveillance.

ProMED/ISID received pilot funding form the Nuclear Threat Initiative to develop a Russian-language PMM service that will focus on the Newly Independent States (NIS). A moderator from Uzbekistan, Nilufar Rakhmanova, was engaged to join the PMM team and with her assistance, ISID is working to develop collaborations with Infectious Disease societies in the NIS, to help PMM develop its Russian-language capacity and to develop ProMED-RUS, a Russian language service.

2004: Jorge Gonzalez-Mendoza of Lima, Peru joined the ProMED-ESP team as moderator and Spanish translator Alexander Peredkov of Kyrgyz Republic and Vadim Melnik of Ukraine joined ProMED's NIS team bringing the total PMM staff to 26 individuals in 12 countries.

By April 2004 PMM reached 34,025 subscribers. Approximately 40,000 monthly visits to our website and countless retransmissions of ProMED's reports via the Internet and traditional media extend our reach to many more.

Ongoing outbreaks of avian influenza, including human cases that threaten a global pandemic, have received prominent reporting during the year.

2005: The outbreak of H5N1 avian influenza that began in 2003 has continued to dominate ProMED's reports as the world stands poised on the brink of the next pandemic. Outbreaks of Marburg and Ebola highlighted the importance of viral pathogens in disease emergence and prompted ProMED to enroll an additional viral disease moderator, Robert C.A. Yang of Taiwan. Daily and Weekly Updates become available providing titles and quick links to all ProMED posts for subscribers wanting a more abbreviated format.

\section{Operation of PMM}

The operation of PMM has recently been described in some detail (1). PMM is a fully moderated listserv, that is, all reports that are posted have been pre-approved and edited by PMM staff. 
Input comes from a variety of sources. First, participant/ subscribers to PMM send information for reports. This may be in the form of first-hand reports, for example, a veterinarian may have noted an outbreak of a cattle disease in a location and report the details in an e-mail to PMM. Many readers send news stories from local or national publications. Others provide additional data related to previously posted reports or 'requests for information'. In addition to this passive receipt of information, the PMM staff and a cadre of volunteer 'rapporteurs' uncover news of emerging diseases from numerous sources. These include the news media and the websites of local, regional, national and international public health and veterinary sites. Many of PMM's subject area moderators subscribe to lists and publications specific to their area of interest that spur reports to ProMED. Our growing panel of regional networks also provides input to the system.

At any given time, the editor or one of four associate editors serves as the 'top moderator,' who is the focal point for all incoming and outgoing outbreak information. This individual reads each e-mail that arrives at PMM (hundreds each day) and makes an initial assessment. Reports that are relevant and potentially valid (approximately 15-20 each day) are forwarded to one of the subject area moderators for further vetting, initial editing and commentary. At present there are one or more expert moderators for parasitic diseases, bacterial diseases, epidemiology, viral diseases, plant diseases, animal diseases and zoonoses. These moderators further verify the validity of reports (often by checking, sometimes by telephone, with alternative sources). Some are rejected or combined with other reports. The remainder of the reports are put into a standard format, with references to outside literature and to prior reports in the PMM archive and commentary on the nature and context of the disease or outbreak.

Reports then flow to a team of copy editors who assure the editorial integrity of the reports and finally back to the top moderator. The top moderator reviews the entire report, decides which of PMM's lists should receive the post, and finally sends the report to the appropriate lists and to the web site. The entire process usually occurs in less than $24 \mathrm{~h}$. In the event of an urgent report, the copy-editing step is bypassed and reports are posted immediately. In this manner, PMM posts an average of seven reports each day, 365 days per year. All reports are archived for easy retrieval by e-mail or through a powerful web site and search engine (provided as a contribution by the Oracle corporation).

\section{Conclusions}

WHO's Weekly Epidemiological Record for 7 January 2000 has an article entitled "An integrated approach to communicable disease surveillance", which includes the following statement (2).
"In the area of epidemic surveillance and response, public health authorities should give more attention to information from sources other than the public health sector, including NGOs and the media [emphasis added]. The capacity of public health authorities to rapidly respond to outbreak-related information from any source is essential for the efficiency and credibility of the entire surveillance effort."

Now in its eleventh year, PMM is a robust and sensitive mechanism for the discovery of emerging disease outbreaks involving humans, animals and plants around the world and rapid dissemination of the information. Fast reporting translates into quicker arrival of prevention and control assistance from other countries, better advance warning to neighboring countries and intending travelers, and other benefits to public health such as heightened awareness of health workers to the threat, time to prepare countermeasures and to react in an appropriate manner rather than with a reflex emergency response. Some travelers may alter their plans to avoid the possibility of contracting the disease; this also protects their home population from spread, in the event that they were to return from their trip with a communicable disease.

PMM also serves as a forum for informed discussion, a mechanism for directing assistance and an early warning system for public health and medical personnel around the world. It is freely available to anyone with an e-mail account. As a program of the International Society for Infectious Diseases, it remains free of political constraints and open to all sources of information. Ongoing development of regional networks, enhanced language capacity, and geographic mapping capabilities promise improved usefulness over time. Readers are encouraged to enroll at PMM's website, http://www.promedmail.org $(3,4)$.

The experience of operating PMM over nearly 11 years has shown that the public, interactive, unofficial reporting of outbreaks can be faster than official channels, yet be reliable and responsive to the needs of healthcare providers in epidemic locales. The constantly expanding number and geographical spread of ProMED-mail subscribers, both health professionals and general public, with an interest in exchanging information on emerging infectious diseases, provides a much larger reporting base than any national or international health organization and an unequalled capacity for discovering and reacting to outbreaks wherever they may occur.

PMM connects by e-mail more than 30,000 people in over 180 countries, who place their computers and time at the network's disposal and report on outbreaks of which they have knowledge. Regions and countries could benefit from adopting the ProMED-mail approach to complement their own disease surveillance systems at minimal cost, because the computers, connection time and operators are provided free by subscribers. All that is needed to begin with is a computer server, free e-mail listserv software such 
as Majordomo, part of the time of a (computer) postmaster, and a qualified moderator (infectious disease or public health specialist). The system should ideally be based in an independent university or NGO that is not subject to government constraints on information flow but must be moderated by health professionals to maintain credibility. Particularly for countries with limited government resources, taking advantage of community resources in this way could be very cost-effective as well as beneficial (5).

\section{Acknowledgments}

Our thanks to the entire PMM staff—all of whom are part-timefor their ongoing efforts on behalf of global public health. PMM gratefully acknowledges grants from the Bill and Melinda Gates Foundation, The Rockefeller Foundation, The Dodge Foundation, ARCO (Atlantic Richfield Corp.), Pfizer Inc., Oracle Corp., the U.S. Departments of Agriculture and Defense, the Nuclear Threat Initiative \& an anonymous donor; gifts from Alan Alda, and from John Marr and John Baldwin, authors of the book The Eleventh Plague: A Novel of Medical Terror, which features ProMED-mail prominently and is dedicated to both ProMED and SatelLife; and cash contributions from subscribers in response to annual 'Internet-a-thon' fundraisers. ProMED-mail is also extremely grateful to Nobel Laureate Dr. Joshua Lederberg for his unflagging backing of its mission. J.W. gratefully acknowledges the support of the New York State Department of Health's Wadsworth Center, the National Research Council of Brazil (CNPq) and the State of Rio de Janeiro's Research Foundation, Brazil. Thanks to Amy Galbum, MPH, for assistance in the preparation of this manuscript.

\section{References}

1. Madoff LC. ProMED-mail: An early warning system for emerging diseases. Clin Infect Dis 2004 2003;39:227-232.

2. WHO (World Health Organization). An integrated approach to communicable disease surveillance. Weekly Epidemiol Rec 2000;75: 1-8. < http://www.who.int/wer/pdf/2000/wer7501.pdf > .

3. Woodall JP. Global surveillance of emerging diseases: the ProMEDmail perspective. Cad Saude Publica 2001;17(Suppl):147-154.

4. Woodall J. Stalking the next epidemic: ProMED tracks emerging diseases. Public Health Rep 1997;112:78-82.

5. Check E. Dispatches from the front line. Nature 2004;432:544-545. 